\title{
A Quantitative Analysis of e/i Variation in Old Irish etar and ceta $^{1}$
}

\author{
Elliott Lash (elliott.lash@nuim.ie) \\ Department of Early Irish \\ Maynooth University
}

\section{Data Overview}

Thurneysen (1946: 510, GOI §835) discusses the prefix/preposition/preverb <etar> (eDIL s.v. eter, etir), which has the following variants: etar, eter, etir, itar, itir, and itar. For simplicity, I will refer to this element as <etar>. I will label the variants as either ()e-variants (etar, eter, etir), or (-)i-variants (itar, itir, itar). Thurneysen is uncharacteristically imprecise in discussing the variation. His commentary on the variation in the initial syllable can be summarized in three points, listed in (1):

1. a. (-)e-variants are common in the Würzburg and Turin Glosses, although (-)i-variants are also found.

b. Before infixed pronouns in Milan one finds both etar and itir.

c. In 'later' Old Irish (the St. Gall and the Karlsruhe Augustine glosses), etar and itar are more common.

This essentially amounts to a list of random features amongst which no similarities can be observed. In a forthcoming paper, Griffith (2016a) clarifies the distribution of some of these variants, concentrating largely on the phonological history of the second vowel. $\mathrm{He}$ also notes that (-)i-variants of <etar $>$ are uncommon and that the variant is limited to pretonic position (i.e., preverbs in deuterotonic compound verbs, and non-conjugated prepositions). In the Würzburg Glosses, he notes 1 out of 32 pretonic examples. In the Milan Glosses, he notes 5 out of 64 pretonic examples. ${ }^{2}$ In the St. Gall Priscian Glosses, he notes 10 out of 36 pretonic examples. He interprets the rarity of the (-)i-variant and the

\footnotetext{
${ }^{1}$ I gratefully acknowledge the help I received on various points in this paper from David Stifter, Aaron Griffith, and Bernhard Bauer.

${ }^{2}$ I have a slightly different count for the Würzburg and Milan Glosses (for full details see the Appendix). I count 33 pretonic examples in Würzburg, with 1 (-)i-variant. I count 69 pretonic examples in Milan with 4 examples having an (-)i-variant.
} 
prevalence of the (-)e-variant as an indication that the pretonic form was originally *etVr and that the (-)i-variant began to gain currency during the course of the Old Irish period. This interpretation, as far as it goes, seems to be sound.

One can expand upon and refine this analysis with a quantitative analysis of the data found in the Würzburg Glosses Lexicon (Kavanagh 2001), the Milan Glosses Database (Griffith 2013), the Priscian Glosses Database (Bauer 2015), the ninth-century glosses in the Minor Glosses Database (Lash, in progress), and the Book of Armagh Additamenta and Stowe Missal Treatise on the Mass (Lash 2014 and Stokes and Strachan 1901). This paper will use a statistical approach to make sense of an additional set of observations about the distribution of the variants of <etar $>$, namely (a) the constraints on the usage of the (-)i-variant, and (b) the time frame for the diffusion of the (-)i-variant.

An examination of the evidence from the two larger and earlier (eighth-century) glossed corpora, the Milan and Würzburg Glosses, reveals that the (-)i-variant appeared in a restricted but very well defined set of circumstances. As mentioned already, Griffith (2016a) showed that all instances of the (-)i-variant are pretonic. Griffith does not, however, note that in most of the examples, the (-)i-variant is further limited. In particular, it is mostly possible in 'pretonic complexes'. This term is not a common one in Irish studies but I suggest that it refer to pretonic clitic chains in compound verbs or noun phrases. This will include the following set of cases:

2. Compound verbs

a. Conjunct particle or preverb + enclitic $^{3}$ ro as aspectual particle.

b. Conjunct particle or preverb + enclitic infixed pronoun.

c. Conjunct particle or preverb + infixed relative mutation.

d. Any grammatical combination of the above three contexts.

3. Noun Phrases: preposition + determiner/numeral $(+ \text { other material })^{4}$

\footnotetext{
${ }^{3}$ I use the word 'enclitic' here to characterize pretonic instances of ro that are attached (i.e. enclitic) to the preverb or conjunct particle. McCone (1997: 154) calls this proclitic ro because it is proclitic to the tonic verbal root.

${ }^{4}$ In this context, Stifter (2014) argues that the post-syncope form should be preposition + short form of the article, i.e. eter na for eter inna. The fact that syncope occurs in this context, even though its effects are
} 
The Milan and Würzburg Glosses have three examples of (2). These are listed in (4). ${ }^{5}$

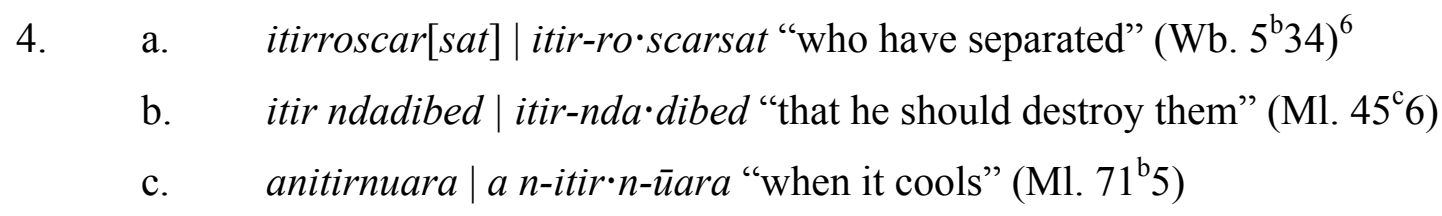

The form itir-ro'scarsat shows the (-)i-variant itir in a pretonic complex with an enclitic $r o$; that is, it is an instance of (2a). This is an especially clear example because of the form the tonic verbal root takes. The verbal root in this example is -scarsat (bolded text indicates the position of the stress). If the root were unstressed, the aspectual particle ro would be stressed. Such a shift in stress would be reflected in a shift in syncope pattern (see McCone 1997: 5). The expected form in that case would be *.roscraiset (compare eter-roscra $\mathrm{Wb} .9^{\mathrm{d}} 31$ ). The enclitic character of the aspectual particle in the form in $\mathrm{Wb}$. $5^{\mathrm{b}} 34$ is therefore assured.

In the two instances of preverbal itir in the Milan Glosses, the preverb is followed by relative nasalization. The preverbal elements in itir-nda·dibed and itir-n-üara are therefore part of a pretonic complex, according to (2c). In the form itir-ndaddibed, moreover, the preverbal elements include an infixed pronoun. The form is doubly complex; thus, it is an instance of (2c) and (2d).

In addition to the cases of verbal pretonic complexes presented above, the Milan Glosses also contain one example of a nominal pretonic complex, which I provide in (5).

5. a. hitar na doinmecha "among the adverse things" (Ml. 38 12)

sometimes obscured by analogy, might imply that the preposition and the definite article form an unstressed clitic chain.

${ }^{5}$ In examples from the glosses I provide first the form found in the manuscript followed by an edited form to which I have added the raised dot - to indicate the divide between pretonic and tonic portions of the verbal complex and hyphens to separate clitic elements and nasalization. I also add macrons to indicate length where there is no accent mark in the manuscript.

${ }^{6}$ The word is actually much more difficult to read than either Stokes and Strachan (1901: 528) or Kavanagh (2001: 412) claim. In the facsimile found on the website of the library of the University of Würzburg (http://vb.uni-wuerzburg.de/ub/foliomagnifier.html?book=49294542\&page $=9$ ) only itirrosca can be read (with difficulty). This is still enough for the argument made in the text to work. 
The constraint on the appearance of (-)i-variants in the Würzburg and Milan Glosses can only be stated in terms of a one-way implication, as follows:

6. (-)i-variants of <etar> in eighth-century glossed manuscripts generally tend to be found in the context of a pretonic complex.

The use of the (-)i-variant instead of the (-)-e-variant is undergoing change probably starting in the late eighth century and stretching into the ninth century, as I will show below. Therefore, the observation in (6) is only a tendency and not a 'rule'. Two types of deviations from (6) are observed. First, there is one instance of an (-)i-variant that is not in a pretonic complex:

7. itir dóini 7 idlu "both men and idles" (M1. 138c1)

Moreover, the opposite tendency from (6), namely "pretonic complexes generally have ()i-variants", is not observed. There are, for instance, six instances of (-)e-variants in preverbal pretonic complexes in the Milan Glosses. Four of these contain etar, even though this is usually the tonic form. These are listed in (8). The other two examples contain the usual pretonic preverb etir in what may be a pretonic complex, according to (2). These are listed in (9).

8. a. etarrusuidige | etar-ru•suidige [d] "it was placed between" (Ml. 27 23 )

b. coetardamdibetsa $\mid$ co etar-dam $\cdot$ dibet-sa

"so that they may destroy me" (Ml. 44'31)

c. coetardamdibitisse $\mid$ co etar-dam $\cdot$ dibitis-se

"so that they might destroy me" (M1. 54 $\left.{ }^{\mathrm{d}} 14\right)$

d. etardanroscarni | etar-dan·roscar-ni "he has separated us" (M1. 120³)

9. a. etirdibnet $\mid$ etir $\cdot$ dibnet "who destroy" $\left(\right.$ Ml. 15 $\left.5^{\mathrm{b}} 6\right)(+$ rel. len.)

b. etirdibnitis | etir.dibnitis "who used to destroy" (M1. 997) (+ rel. len.) 
The forms in (8) show a pretonic complex containing an enclitic aspectual particle (8a) and three instances of a pretonic complex containing infixed pronouns ( $8 b-d)$. The forms in (9) show that etir is found in relative position (most likely a leniting relative clause).

Finally, there is one instance (ex. 10) in the Milan Glosses of the form etir in a prepositional relative clause, a context which could be subsumed under (2) as well, given that the preposition + relative particle in such contexts was undoubtedly an unstressed pretonic clitic cluster. ${ }^{7}$

10. etiratórbie | etir-a·tórbie "among which you will come" (M1. 135 2 )

\section{Hypotheses}

In the following section of the paper, I will explore the above data further with quantitative methods in order to show that (a) the distribution of the different variants is not random, and (b) the distribution significantly changes over time. To be more precise, I propose to test the two hypotheses listed in (11).

11. a. Hypothesis 1: In the eighth century, (-)i-variants tend to occur, to a statistically significant degree, in pretonic complexes, as opposed to anywhere else.

b. Hypothesis 2: In the ninth century, the link between (-)i-variants and pretonic complexes is lost.

\footnotetext{
${ }^{7}$ A phonologically identical environment is found in the rare instances of the infixed relative morpheme - $e$ $/-a$ - in compound verbs other than those with $\mathrm{ar}$. and $\mathrm{imm} \cdot$ as first preverb. A relatively comprehensive corpus of such examples is found in Breatnach (1994). Breatnach mentions four examples containing an ()i-variant of the preverb <etar>. They all come from a possibly separate section of the law text Miadslecthae. For some discussion about this text and further references, see Kelly (2009: 267) and Breatnach (2005: 264). Like most law texts, this text is preserved in late medieval manuscripts. the evidential value of the variants is therefore limited. Breatnach is non-committal on the age of this usage with preverbs other than $\mathrm{ar} \cdot$ and $\mathrm{imm}^{*}$, raising the question of whether the usage is a relic of older usage or exclusively innovative. One example is given below, edited according to the principles laid out in footnote 5.

i. Is cumal iter- $a \cdot$ tha a ndìre.

'It is a cumal which is between the compensations due to them." (CIH 588.26)

cf. also CIH 588.34, 589.1, 589.2
} 
Before moving on to test these hypotheses, a second lexical item $<$ ceta $>$, which shows similar variation, must be introduced. The preverbal adverb <ceta $>$ has two basic variants: the (-)e-variant ceta and the (-)i-variant cita. Griffith (2016b) gathered the evidence for this preverb from the Würzburg, Milan, St. Gall Glosses and some ninthcentury Minor Glosses. He notes that the (-)e-variant of ceta is more common in the Würzburg Glosses while the (-)i-variant is more common in the Milan Glosses. He then compares the e/i-variation of $<$ ceta $>$ to the e/i-variation of $<$ etar $>$ and notes that the ratio of (-)e/i-variants of $<$ etar $>$ is not the same as the ratio of (-)e/i-variants of $<$ ceta $>$. He makes three claims about this variation, which are listed in (12).

(12) a. The (-)e-variant of ceta is earlier than the (-)i-variant, which is innovative.

b. The innovation of the (-)i-variant of $<$ etar $>$ and $<$ ceta $>$ may have been part of a general reduction of vowel in clitics in the later eighth century.

c. The difference between the ratios of the variants of $\langle$ etar $>$ and $\langle$ ceta $>$ is due to paradigmatic pressure on $<$ etar $>$, to which $<$ ceta $>$ is not subject.

I will show in section two that (12b) does not seem to be the correct inference. Rather, I will argue that the (-)i-variant must have been an innovation of the early eighth century and that a significant starting context for it was in pretonic complexes in both $<$ etar $>$ and $<$ ceta $>$. I also show that the (-)i-variant of <etar $>$ became common in unstressed positions in the ninth century.

\section{Quantitative Discussion}

\subsection{Correlation between Pretonic Complexes and the (-)i-variant of $<e t a r>$.}

I would first like to determine if there is a statistically significant relationship between the pretonic complexes and the vowel of the first syllable of <etar $>$. I will be concerned here only with the Milan Glosses, as a representative sample for the (late) eighth century. 
There are two variables I am interested in: complex type and variant type. Each variable has two possibilities. The two possibilities for the first variable that I am interested in are: pretonic complex or non-pretonic complex. I use these terms in the following way. The term 'pretonic complex' refers to instances of $<$ etar $>$ as a pretonic preverb or preposition in a clitic cluster (see ex. 2-3 above). 'Non-pretonic complex' refers both to instances of etar as a pretonic preverb or preposition not in a clitic cluster, or as a tonic preverb, nominal prefix or prepositional pronoun. The two possibilities for the second variable are: the (-)e- or the (-)i-variants. A table showing the distribution of the data follows.

Pretonic complex Non-pretonic complex Total

Table 1: e/i variation in etar in the Milan glosses

$\mathbf{P}=.0112$ (Two-Tailed Fisher's Exact Test)

$\mathrm{P}=.000072$ (Two-Tailed 2 Population Proportion z-test)

The p-value for the Fisher's Exact Test is statistically significant and means that the null hypothesis that there is no relationship between the two variables can be rejected. This implies that the likelihood that a pretonic complex has one variant is significantly different from the likelihood that a non-pretonic complex has that particular variant.

Now that the first test has shown that a relationship between the two variables is likely, I would like to see if the vowel variant associated with each complex type can be determined. To do this, I used a Two-Tailed 2 Population Proportion Z-test on the data in Table 1. I compared the proportion of pretonic complexes with the (-)i-variant (12\%) to the proportion of non-pretonic complexes with the (-)i-variant (.7\%). The p-value for this test means that the null hypothesis can be rejected, and therefore that the difference between the two proportions is significant. This implies that the (-)i-variant is associated with pretonic complexes significantly more often than the (-)e-variant.

\subsection{Change in distribution of the (-)i-variant of etar over time.}


Having established that there is a correlation between the (-)i-variant and pretonic complexes, I want to determine if this situation was stable or subject to diachronic change. There are again two variables that I am interested in: time and initial vowel of $<e t a r>$. Each variable has two variants. For the first variable, the two variants are eighthcentury examples and ninth-century examples. The eight-century examples consist of all the examples of <etar> (preverbal, prepositional, nominal prefix, and prepositional pronouns) from the Würzburg Glosses combined with all the examples from the Milan Glosses. The ninth-century examples consist of all the examples of $<$ etar $>$ from the St. Gall Glosses combined with all the examples from the Minor Glosses, the Book of Armagh, and the Stowe Missal. ${ }^{8}$ The two variants for the second variable are, again, the (-)e-variant and (-)i-variant.

\begin{tabular}{|llll|}
\hline All Ex. & e & i & Total \\
\hline $\mathbf{8}^{\text {th }} \mathbf{c .}$ & 242 & 5 & 247 \\
$\mathbf{9}^{\text {th }} \mathbf{c .}$ & 81 & 23 & 104 \\
Total & 323 & 28 & 351 \\
Table 2: & Variants of $<$ etar $>$ across time \\
$\mathbf{P}<.0001$ & (Two-Tailed Fisher's Exact Test) \\
\hline
\end{tabular}

The p-value means that the null hypothesis that there is no change between the eighth and ninth century in the distribution of the vowels variants can be rejected. This therefore implies that it is more likely in a ninth-century manuscript that the word <etar> would have the (-)i-variant than it was in the eight-century. Conversely it is more likely that an eight-century manuscript would have the (-)e-variant. ${ }^{9}$

\footnotetext{
${ }^{8}$ These glossed corpora frequently contain various chronological strata. For instance, a large part of the Philargyrius glosses may in fact be much older than the ninth century. It is typically thought that they are to be dated to the seventh century. There is however some evidence for intermediate stages of transmission. The same can be said of the St. Gall glosses. So, there is always some doubt over which layer a particular variant can be ascribed to. Given the weight of the evidence, I prefer to see the (-)i-variant as innovative wherever it is found. It therefore may be ascribed to the ninth century glossatory/copyist of any given manuscript.

${ }^{9}$ The same p-value is obtained if only pretonic examples of $<$ etar $>$ (i.e. preverbal and prepositional) are tested. These data are gathered in the following table.
}

\begin{tabular}{|llll|}
\hline Pretonic Examples & e & i & Total \\
\hline $\mathbf{8}^{\text {th }}$ c. & 102 & 5 & 107 \\
$\mathbf{9}^{\text {th }}$ c. & 34 & 21 & 55 \\
Total & 136 & 26 & 162 \\
Table: Variants of pretonic $<$ etar $>$ across time \\
\hline
\end{tabular}




\subsection{Change in distribution of the (-)i-variant of ceta over time.}

Thus far, I have shown that there is a significant correlation between the (-)i-variant of $<$ etar $>$ and the pretonic complex position. I have also shown that the use of the (-)ivariant increases over time, especially in the pretonic position. We have seen in the general discussion (section 1) that the pretonic preverb <ceta $>$ also shows the same variants. Given that I have shown that the vowel-variant variable is dependent on the complex type variable, we might expect that the distribution of vowel variants of ceta to undergo a similar change to the variants of <etar>. As mentioned above, Griffith (2016: 2, fn.3) showed that the Würzburg Glosses and the Milan Glosses have a significantly different distribution of (-)e- and (-)i-variants of the preverbal adverb $<$ ceta $>$. I reproduce his data here along with the p-value from the Fisher's Exact Test that he performed.

\begin{tabular}{|llll|}
\hline Würzburg & ceta & cita & Total \\
Milan & 3 & 0 & 3 \\
Total & 1 & 5 & 6 \\
Table 3: Variants of $<$ ceta $>^{\text {over }}$ time. $^{\mathbf{1 0}}$ \\
$\mathrm{P}=0.0476$ (Two-Tailed Fisher's Exact Test)
\end{tabular}

The p-value means that the null hypothesis that there is no difference between the Milan and the Würzburg Glosses can be rejected. This implies that the (-)i-variant of $\langle$ ceta $>$ is significantly more common in the Milan Glosses (late eighth century) than in the Würzburg Glosses (early eighth century). Given that the test on table 2 showed that the

$\mathrm{P}=.0001$ (Two-Tailed Fisher's Exact Test)

The null hypothesis is that neither vowel variant in pretonic examples of <etar $>$ should be more likely to occur in a given century. The p-value means that the null hypothesis can be rejected. This implies there is a correlation between a particular century and a particular variant. It appears that the (-)i-variant becomes more prevelant in the ninth century in contrast to the eighth century.

${ }^{10}$ Data:

Würzburg Glosses (-)e-variant: Wb. $7^{\mathrm{b}} 11$, Wb. $14^{\mathrm{a}} 29, \mathrm{~Wb} .21^{\mathrm{c}} 5$, Wb. $26^{\mathrm{c}} 4$.

Milan Glosses (-)e-variant: M1. $124^{\mathrm{b}} 3$.

Milan Glosses (-)i-variant: M1. 38 3 , M1. 39 15 , M1. 44 ${ }^{\mathrm{b}} 4$, M1. 86 ${ }^{\mathrm{d}} 19 \mathrm{a}, \mathrm{M} 1.125^{\mathrm{d}} 4$.

Griffith (2016b) counts Wb. 14a29 ciatu-ru·chreitset as an (-)e-variant. Presumably this is because $<$ ia $>$ is sometimes used as an (archaic?) alternative to $<\mathrm{e}>$ (Thurneysen 1923, Greene 1972, Jasanoff 1999), but this is not explicitly stated. Since the form of $<$ ceta $>$ in this example is very definitely a pretonic-complex due to the enclitic ro along with the relative lenition, it is perhaps not surprising that the vowel is written in a peculiar way. 
distribution of the initial vowel of <etar $>$ changed between the eighth and ninth-century manuscripts, we might expect that ninth-century manuscripts would also show that the change in the distribution of the variants of $\langle$ ceta $\rangle$, implied by the data in table 3 , had continued. In order to test this hypothesis, all eighth-century examples (Würzburg + Milan Glosses) of $<$ ceta $>$ were compared to all ninth-century examples (St. Gall + Minor Glosses + Book of Armagh + Stowe Missal). The null hypothesis is that there is no change in the distribution of the (-)e- or (-)i-variants of the word $<$ ceta $>$ over time.

$\begin{array}{llll} & (-) \text { e- } & (-) \mathbf{i}- & \text { Total } \\ \mathbf{8}^{\text {th }} \text { c. } & 4 & 5 & 9 \\ \mathbf{9}^{\text {th }} \text { c. } & 0 & 3 & 3 \\ \text { Total } & 4 & 8 & 12\end{array}$

Table 4: Variants of $<$ ceta $>$ across time. ${ }^{11}$

$\mathrm{P}=.4909$ (Two-Tailed Fisher's Exact Test)

The p-value means that the null hypothesis cannot be rejected. This is initially surprising from the point of view of Griffith's finding that there are significantly more (-)i-variants in the Milan Glosses as compared to the Würzburg Glosses. The change in the distribution of the variants of $<$ ceta $>$ that occurred in the eighth century does not seem to have continued into the ninth. This is also different from the change affecting the variants of $<$ etar $>$, which as we have seen showed a significant difference between the eighth and ninth centuries. So, even though the initial appearance of variation in both words occurred at some point in the eighth century, <ceta $>$ appears to have developed in one direction, while <etar> appears to have done something different. The data seem to not only make a certain amount of sense, but point to very interesting conclusion. Essentially, the difference between $<$ ceta $>$ and $<$ etar $>$ is one of time: $<$ etar $>$ shifted from the (-)e- to (-)i-variant later than $<$ ceta $>$ did. While $<$ ceta $>$ completed this change by the late eighth century, the change in the distribution of variants of $<$ etar $>$ occurred in the ninth century.

\subsection{Measuring the difference between $<$ ceta $>$ and $<$ etar $>$}

${ }^{11}$ Griffith (2016b) lists the following ninth-century examples: Tur. Mark Thes.i.488.60; K. Bede Thes.ii.23.38, Arm. Add. Thes. ii 241.15-16. 
The question that should be answered now is why did $<$ ceta $>$ and $<$ etar $>$ behave so differently? One way of approaching this problem is to compare the distribution of (-)eand (-)i-variants in the pretonic-complex examples of $<$ etar $>$ to the distribution of such variants in examples of $<$ ceta $>$, which are all in pretonic complexes ${ }^{12}$, and see whether there is a relationship between a form $(<e t a r\rangle$ or $<$ ceta $>)$ and one of the vowel variants. The null hypothesis is that there is no relationship between the vowels variants and

${ }^{12}$ Griffith (2016b) mentions two instances of preverbal $<$ ceta $>$ in the Milan Glosses that would not be classified as appearing in pretonic complexes by the usual grammar of Classical Old Irish. These are Ml. and $39^{\mathrm{c}} 15$ (i) and $86^{\mathrm{d}} 19 \mathrm{a}$ (ii).

i. $\quad$... combad frisnagruade 7 frisnaforbru citacommairsed ...

"...so that it might be against the cheeks and against the eyebrows that it would first meet..."

ii. . . airni doib citarochet "for it is not to them that it was first sung."

In both examples, the verb prefixed by the (-)i-variant cita is found in a prepositional cleft construction. In Classical Old Irish the verb in this construction did not display any relative morphology. While arguing for the presence of a Cowgill Particle (*eti, following Schrijver 1994 and Schumacher 2004) that preserves the final vowel of the preverb $\langle$ ceta $\rangle$, Griffith rejects the possibility that cita in the above two examples could have contained a relative particle at some previous point in their derivation. In essence, therefore, he views these examples as good evidence for the Classical Old Irish prepositional cleft construction. However, there is evidence that in the Milan Glosses verbs in prepositional clefts could display relative morphology. McCone (1985: 96) mentions two such examples: Ml. $45^{\mathrm{a}} 8$ and $64^{\mathrm{a}} 14$, the first of which I reproduce here (iii).

iii. acht is do sochaidi no-pridchib

"but it is to a multitude that I will preach" (for Classical Old Irish: **pridchaifea)

If the two (-)i-variants in $39^{\mathrm{c}} 15$ and $86^{\mathrm{d}} 19 \mathrm{a}$ also represent examples of this variant syntax for prepositional clefts, then they are both further instances of pretonic complexes, since they both contain a (null) relative morpheme.

Note, in the Milan Glosses Database (Griffith 2013), Griffith proposes a different analysis for (iii). He claims that the verb contains an unwritten $2^{\text {nd }}$-person singular infixed pronoun to explain "the otherwise unexplainable presence of no-." It is very unlikely that this is the correct interpretation, since there is no reason for a $2^{\text {nd }}$-person pronoun here at all. For $64^{\mathrm{a}} 14$, Griffith merely notes that the lenition of after $r u$ - is unexpected. 
whether the word is <etar $>$ or $<$ ceta $>$. That is to say, neither word favors one vowel variant over the other. A table showing the distribution of the data follows:

\begin{tabular}{llll|}
\hline & $\mathbf{( - ) e}-$ & $\mathbf{( - ) i -}$ & Total \\
$<$ etar $>$ & 22 & 3 & 25 \\
$<$ ceta $>$ & 1 & 3 & 4 \\
Total & 23 & 6 & 29 \\
Table 5: & e/i variation in $<$ etar $>$ and $<$ ceta $>$ in the Milan glosses \\
$\mathbf{P = . 0 2 0 0}$ (Two-Tailed Fisher's Exact Test) \\
$\mathbf{P = . 0 0 3 8 6}$ (Two-Tailed 2 Population Proportion z-test)
\end{tabular}

The p-value for the Fisher's Exact Test is statistically significant and means that the null hypothesis can be rejected. This implies that one word favors one of the variants over the other. The precise variant that each word favors can be determined using a z-test. This test shows that the proportion of (-)e-variants of $<$ etar $>(88 \%)$ is significantly greater than the corresponding proportion of (-e)-variants of $<$ ceta $>(25 \%)$. So, it appears that by the end of the eighth century, cita was the preferred form of $<$ ceta $>$ in pretonic complexes (i.e. all available examples), while etar was the preferred form of $<$ etar $>$. This is true despite the fact that (-)i-variants of <etar $>$ are significantly more likely to appear in pretonic complexes as opposed to non-pretonic complexes (see the discussion associated with Table 1). This tension between the large number of pretonic (-)e-variants of $<$ etar $>$ and the significant likelihood of (-)i-variants appearing in that position was resolved in the ninth century by the drastic spread of (-)i-variants of <etar> (see the discussion associated with Table 2).

\subsection{Comparison between $<$ etar $>$ and $<$ ceta $>$ solely in pretonic preverbal complexes}

One might argue that the apparent predominance of (-)e-variants of <etar $>$ as opposed to (-)i-variants of $<$ ceta $>$ revealed by the tests associated with Table 5 is misleading since there are intrinsically more examples of pretonic complexes containing <etar $>$ (preverbal + prepositional) than examples of pretonic complexes of containing $<$ ceta $>$ (preverbal only). In other words, the comparison in section 2.4 is not exact. A putatively better way of comparing the distribution of the variants of the words is by focusing on only those 
instances of etar that are solely preverbs. The relevant data is collected in Table 6. Here, the null hypothesis is that in pretonic preverbal complexes neither word is more likely to be associated with a particular variant.

\begin{tabular}{|llll|}
\hline & (-)e- & (-)i- & Total \\
etar & 6 & 3 & 9 \\
ceta & 1 & 3 & 4 \\
Total & 7 & 6 & 13 \\
Table 6: & e/i variation in & etar and ceta in preverbal complexes in the Milan Glosses \\
$\mathrm{P}=0.2657$ & (Two-Tailed Fisher's Exact Test) \\
$\mathrm{P}=0.16452$ & (Two-Tailed 2 Population Proportion z-test) \\
\hline
\end{tabular}

The p-value of the Fisher's Exact Test is not statistically significant. This means that the null hypothesis must be upheld. Thus, the likelihood that either variant of $<$ etar $>$ appears in pretonic preverbal complexes is the same as the likelihood of either variant of $\langle$ ceta $>$ appearing. The tension observed above between the two different results for $<$ etar $>$, i.e. the large number of (-)e-variants of <etar $>$ in pretonic complexes and the significant likelihood that (-)i-variants appears in pretonic complexes, can be put into context. With regard to the large number of (-)e-variants, one might note that many examples of <etar $>$ in pretonic complexes are in fact prepositions and these usually have the (-)e-variant. As for the preference for (-)i-variants to appear in pretonic complexes, this is likely to mean precisely that (-)i-variants of <etar> are marginally more likely in pretonic verbal complexes. This is of course unsurprising if the likelihood of either variant of $<$ etar $>$ to appear in pretonic verbal complexes in the Milan Glosses is the same as the likelihood of either variant of $\langle$ ceta $>$ appearing in those contexts, and if $\langle$ ceta $>$ is significantly more likely to have an (-)i-variant (see the discussion associated with Table 5). The upshot of this is that marginal likelihood of (-)i-variants appearing in pretonic verbal complexes was a sufficient basis for the eventual spread of (-)i-variants to most positions by the ninth century. That is, whatever pressure non-pretonic complexes asserted on the maintenance of (-)e-variants of <etar $>$ in the eight century was not sufficient to maintain them into the ninth.

\subsection{The spread of (-)i-variants to non-tonic positions in the ninth century}


Finally, I would like to show that the correlation between complex type and variant type, which I showed to be present in the eight century, became a significantly less important factor in the ninth century. To show conclusively that the ninth century was the period in which the (-)i-variant became prevalent outside of the original pretonic complex, I performed another Fisher's Exact Test using data for the ninth-century manuscripts (St. Gall + Minor Glosses + Book of Armagh + Stowe Missal). The data is found in Table 7. In this table, 'pretonic complex' refers to instances of <etar $>$ as pretonic preverbs or prepositions in a clitic complex. 'Non-pretonic complex' refers both to instances of etar as a pretonic preverb or preposition not in a clitic cluster, or as a tonic preverb, nominal prefix or prepositional pronoun. These are the same conditions as in the eighth data in Table 1, to which the results below should be compared. The null hypothesis is that there is no relationship between complex type and variant.

\begin{tabular}{|llll|}
\hline & e & i & Total \\
Pretonic Complex & 9 & 5 & 14 \\
Non-Pretonic Complex & 73 & 18 & 91 \\
Total & 82 & 23 & 105 \\
Table 7: e/i variation in & etar in the ninth-century manuscripts \\
P=0.1830 (Two-Tailed Fisher's Exact Test)
\end{tabular}

The p-value is not significant. This means that the null hypothesis must be kept. Thus, in the ninth century, unlike the eighth century, there is no relationship between complex type and variant type. This implies that between the late eighth-century Milan Glosses and the ninth-century manuscripts, the (-)i-variant of <etar $>$ gained ground on the (-)evariant, since there was no longer any connection made between pretonic-complex position and the (-)i-variant. The contexts to which the (-)i-variant spreads are almost all unstressed. Essentially, the (-)i-variant is generalized in pretonic prepositions and preverbs, no matter whether they are part of a clitic complex or not.

There are two examples in which the generalization to unstressed position does not straightforwardly apply. The first is the adverbial particle itir in Sg. $90^{\mathrm{a}} 2$ (for more details see eDIL s.v. etir). This derives from the third person singular masculine/neuter conjugated form of the preposition, which would have been stressed. It may be that the 
adverbial particle usage patterns differently with regard to stress. In particular, it could be that the adverbial particle was unstressed. If so, it would not constitute a counterexample to the generalization above.

The second example is itersnidith, a word for "spider" in the glosses on Augustine's Enchiridion (f. 80b; Stern 1910: 492, \#86, eDIL s.v. etersnídid). This is most likely a secondary and partially artificial formation from an unattested verb *etar'sní 'spin between' with the innovative agent suffix -thid/-tid (Thurneysen 1946: 171, GOI $\S 267)$. The ninth-century glossator probably was familiar with the (-)i-variant of <etar $>$ in unstressed positions and may have thought of the verb as *iter·sní, from which the attested noun follows directly.

\subsection{Conclusion to Quantitative Investigation}

The result of the quantitative investigation partly confirms Griffith's analysis, but also gives a slightly more nuanced view on the developments affecting the (-)e-variant and the (-)i-variant. The (-)i-variant first appeared in pretonic complexes and it appears that the words $<$ ceta $>$ and $<$ etar $>$ distribute the variants similarly where possible, i.e. precisely in these pretonic (verbal) complexes. Moreover, <ceta $>$ was intrinsically more likely than $<$ etar $>$ to generalize the (-)i-variant, because $<$ ceta $>$ was always found in a pretonic complex. In other words, there was no pressure on $<$ ceta $>$ to retain its (-)e-variant once the (-)i-variant appeared in pretonic-complex position. This meant that the (-)e-variant of $<$ ceta $>$ became quickly obsolete, during the eighth century. There was, however, paradigmatic pressure against the quick obsolescence of the (-)e-variant of $\langle$ etar $>$, since there were tonic forms, namely conjugated prepositional forms, tonic preverbs, or nominal prefixes, which typically had the (-)e-variant. Thus far, I follow Griffith (2016b).

Eventually, however, the (-)i-variant became available in positions different from its original pretonic complex context. This means that the (-)i-variant never became marginalized despite the paradigmatic pressure. This could be due to the fact that (-)ivariants were always marginally more prevalent in pretonic verbal complexes for $<$ etar $>$, and the general rule for $\langle$ ceta $\rangle$. The combined pressure of these two words in this 
particular unstressed position may have worked in tandem to counter the effects of the paradigmatic pressure.

The main difference between the eighth and ninth century seems to be the linguistic level to which one must appeal for explaining the distribution of the variants. In the eighth century, the few (-)i-variant forms are morpho-phonological variants: they are constrained for the most part to pretonic clitic complexes. In contrast, it seems that the ninth century was a period of extensive diffusion for the (-)i-variant, after it was no longer linked to a particular morpho-phonological context. Rather, the variant was generalized into all unstressed positions (with the exception of the word itersnidid, which has a special origin). Therefore, instead of appealing to the interface between morphology and phonology, it is sufficient to appeal to the level of prosody/phonology alone. With caution, this difference in the distribution can be utilized as a means of dating undated texts. I suggest that undated texts in which the distribution of the (-)i-variant of <etar> can be understood purely phonologically may, in combination with the consideration of other features, be dated more readily to the ninth century or later, rather than to the eighth century or earlier.

\section{Appendix: Data}

For all collections (Tables A-C), all prepositional and preverbal examples are pretonic and pretonic complexes are in Bold.

\section{Milan Glosses}

\begin{tabular}{|l|c|c|c|c|c|c|}
\hline Variant & Prep. & Preverb & Prefix & Conj. Prep. & Adv. Conj. Prep. & Total \\
\hline (-)e- & 41 & 28 & 57 & 6 & 29 & 161 \\
\hline (-)i- & 2 & 2 & 0 & 0 & 0 & 4 \\
\hline Total & 43 & 30 & 57 & 6 & 29 & 165 \\
\hline
\end{tabular}

Table A: $<e t a r>$ in the Milan Glosses

Table A tabulates the examples below.

\subsection{Prepositional $<$ etar $>$}

\subsection{1 (-)e-variant (41, 16 pretonic complexes)}

Ml. 18 24 , Ml. $19^{\text {d }}$ 2, Ml. 19 20 , Ml. 24 25 , Ml. 24d 26 , Ml. $25^{\text {d }} 1$, Ml. $26^{\mathrm{b}} 1$, Ml. $34^{\mathrm{d}} 20$, Ml. $35^{\mathrm{a}} 19$, Ml. $37^{\mathrm{d}} 10$, Ml. $38^{\mathrm{b}} 1$, Ml. $\mathbf{3 8}^{\mathrm{d}} 13$, Ml. 39 ${ }^{\mathrm{a}}$, Ml. $39^{\mathrm{c}} 12$, Ml. $47^{\mathrm{c}} 18$, Ml. $53^{\mathrm{d}} 12$, MI. 56 ${ }^{\text {b } 33}$, Ml. 58 11 , Ml. 59 19 , Ml. $65^{\mathrm{b}} 11$, Ml. $69^{\mathrm{a}} 18$, MI. $\mathbf{7 6}^{\mathrm{c}} \mathbf{5}$, Ml. $92^{\mathrm{a}} 13$, Ml. $97^{\mathrm{a}}$, 


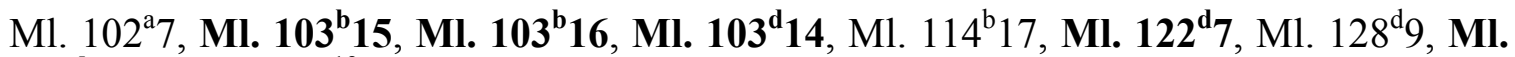
135 $^{\text {d }}$, Ml. $136^{\mathrm{c}} 1 . \mathrm{a}^{13}$, Ml. $136^{\mathrm{c}} 1 . \mathrm{b}$, Ml. $136^{\mathrm{c}} 3$, Ml. 136 4 .a, Ml. 136 4 .b, Ml. $137^{\mathrm{c}} 8$, Ml. 138 $^{\text {d }}$, Ml. $140^{\text {a }}$ 2.a, Ml. $140^{\mathrm{a}}$ 2.b.

\subsection{2 (-)i-variant $(2,1$ pretonic complexes)}

Ml. 38 ${ }^{\mathrm{a}} 12$, Ml. $138^{\mathrm{c}} 1$

\subsection{Preverbal $<$ etar $>$}

\subsection{1 (-)e-variant (28, 6 pretonic complexes)}

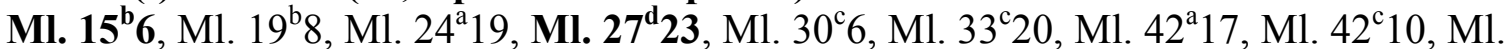

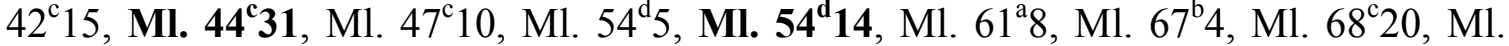

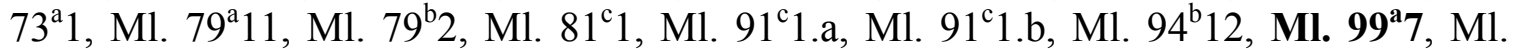
$102^{\mathrm{a}} 22$, Ml. $114^{\mathrm{c}} 8$, Ml. $120^{\mathrm{a}} 3$, Ml. $123^{\mathrm{b}} 10$.

\subsection{2 (-)i-variant $(2,2$ pretonic complexes)}

Ml. $45^{\mathrm{c}} 6$, Ml. $71^{\mathrm{b}} 5$.

\subsection{Nominal Prefix <etar $>$}

\subsection{1 (-)e-variant (57)}

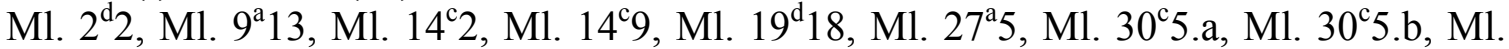

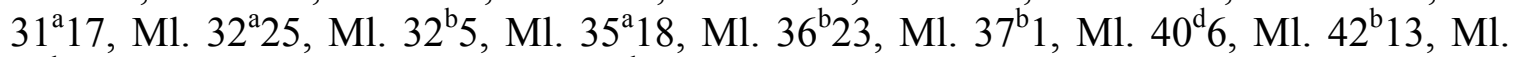

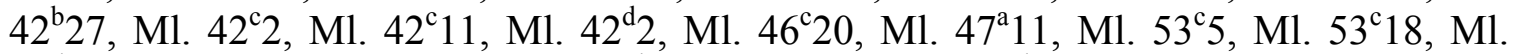

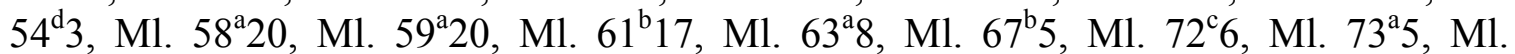

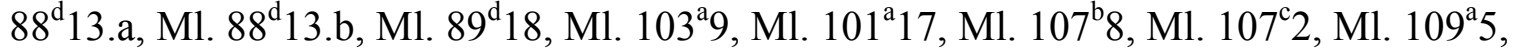
Ml. $110^{\mathrm{c}} 9$, Ml. $110^{\mathrm{d}} 14$, Ml. $111^{\mathrm{b}} 09$, Ml. $111^{\mathrm{c}} 10$, Ml. $111^{\mathrm{c}} 18$, Ml. 113 4 , Ml. 114 ${ }^{\mathrm{b}}$, Ml. $117^{\mathrm{d}} 1$, Ml. $120^{\mathrm{b}} 2$, Ml. $123^{\mathrm{b}} 11$, Ml. $124^{\mathrm{b}} 06$, Ml. 129 13 , Ml. 138 12 , M1. 135 13 , M1. $138^{\mathrm{b}} 4$, Ml. $138^{\mathrm{d}} 3$, Ml. $140^{\mathrm{b}} 2$.

\subsection{Conjugated Preposition <etar $>$}

\section{$1.4 .1 \quad$ (-)e-variant (6)}

Ml. $38^{\mathrm{c}} 28^{14}$, Ml. $72^{\mathrm{c}} 9$, Ml. $78^{\mathrm{b}} 11$, Ml. $112^{\mathrm{a}} 8$, Ml. $119^{\mathrm{d}} 10$, Ml. $131^{\mathrm{c}} 17$.

\footnotetext{
${ }^{13}$ This example, in combination with $136^{\mathrm{c}} 1 . \mathrm{b}$, is a special construction in which the two items governed by $<$ etar $>$ are each preceded by a form of $<$ etar $>$.

i. $\quad$ i. duuc duaid á sed exaltaui animam meam etir sí non humiliter sentiebam 7 etir sicut lactans gaudet 7 causa metri duronad sin "i.e. David has put sed exaltaui animam meam between si non humiliter sentiebam and sicut lactans gaudet, and [it is] causa metri that that has been done."

The construction in (i) can be schematized as $<$ etar $>+\mathrm{X}$ ocus $<$ etar $>+\mathrm{Y}$. The gloss given here is the only instance of this construction in Milan. The same construction is found in $\mathrm{Sg}$. $27^{\mathrm{a}} 18$. The more usual construction in both glossed corpora is rather <etar $>+\mathrm{X}$ ocus $\mathrm{Y}$.

14 This is a possibly lengthened (-)e-variant: étrunn.
} 


\subsection{Adverbial Conjugated Preposition <etar $>$}

\subsection{1 (-)e-variant (29)}

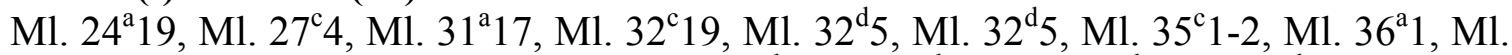
$37^{\mathrm{c}} 13$, Ml. $44^{\mathrm{c}} 2$, Ml. $46^{\mathrm{a}} 14$, Ml. $51^{\mathrm{a}} 1$, Ml. $56^{\mathrm{d}} 2$, Ml. $61^{\mathrm{b}} 12$, Ml. $63^{\mathrm{d}} 1$, Ml. $69^{\mathrm{b}} 3$, Ml. $73^{\mathrm{c}} 5$,

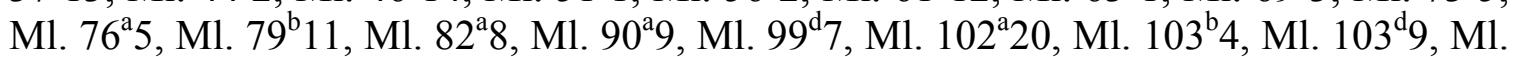
$106^{\mathrm{d}} 11$, Ml. $107^{\mathrm{d}} 12$, M1. $114^{\mathrm{b}} 8$, Ml. $117^{\mathrm{d}} 4$.

2. St. Gall, Ninth-Century Minor Glosses, the Book of Armagh and the Stowe Missal

\begin{tabular}{|l|c|c|c|c|c|c|}
\hline Variant & Prep. & Preverb & Prefix & Conj. Prep. & Adv. Conj. Prep. & Total \\
\hline (-)e- & 25 & 9 & 32 & 10 & 5 & 81 \\
\hline (-)i- & 16 & 5 & 1 & 0 & 1 & 23 \\
\hline Total & 41 & 13 & 33 & 10 & 6 & 104 \\
\hline
\end{tabular}

Table B: Ninth century <etar> (Sg., Minor Glosses, Arm. Add. and Stowe Miss.)

Table B tabulates the examples below.

\subsection{Prepositional $<$ etar $>$}

\subsection{1 (-)e-variant (25, 7 pretonic complexes)}

Sg. $2^{\text {b }} 2^{15}$, Sg. $5^{\text {a }} 9$, Sg. $5^{\text {a }} 12$, Sg. $10^{\text {a}} 4$, Sg. $12^{\text {b }} 6$, Sg. $17^{\text {b }} 1$, Sg. $27^{\text {a }} 4$, Sg. $27^{\text {a }} 9$, Sg. $2^{\text {a }} 18 . \mathbf{a}$, Sg. $27^{\mathrm{a}}$ 18.b, Sg. $\mathbf{2 8}^{\mathrm{a}}$ 7, Sg. $\mathbf{4 5}^{\mathrm{b}} \mathbf{1 9}$, Sg. $51^{\mathrm{b}} 2$, Sg. $51^{\mathrm{b}} 11$, Sg. $54^{\mathrm{b}} 3$, Sg. 59 $9^{\mathrm{a}} \mathbf{1 7}, \mathrm{Sg} .61^{\mathrm{b}} 3$, Sg. $72^{\mathrm{a}} 1$, Sg. $\mathbf{7 2}^{\mathrm{a}} 2$, Sg. $\mathbf{1 5 0}^{\mathrm{b}} 1, \mathrm{Sg} .151^{\mathrm{b}} 7, \mathrm{Sg} .152^{\mathrm{a}} 1, \mathrm{Sg} .185^{\mathrm{b}} 1, \mathrm{Sg} .212^{\mathrm{a}} 11, \mathrm{Sg} .215^{\mathrm{a}} 1$.

\subsection{2 (-)i-variant (16, 4 pretonic complexes)}

Sg. 18 2 , Sg. 20 ${ }^{\mathrm{b}}$ 9, Sg. $68^{\mathrm{b}} 4$, Sg. $162^{\mathrm{a}} 6$, Sg. $163^{\mathrm{b}} 6,218 \mathrm{a}$, Sg. $\mathbf{2 0 3}^{\mathrm{a}} \mathbf{1 6}$, Sg. $203^{\mathrm{b}} 9$, Sg. $212^{a} 15$, K. Aug. Thes.ii.1.2 1, Phil. Thes.ii.47.28, Arm. Add. Thes.ii.238.19, Arm. Add. Thes.ii.239.15, Stowe Missal Thes.ii.252.14, Stowe Missal Thes.ii.253.1, Stowe Missal Thes.ii.255.5.

\subsection{Preverbal <etar $>$}

\subsection{1 (-)e-variant (9, 2 pretonic complexes)}

Sg. 14 4 , Sg. $29^{\mathrm{b}} 2$, Sg. $73^{\mathrm{a}} 14$, Sg. $73^{\mathrm{b}} 2$, Sg. $157^{\mathrm{b}} 10$, Sg. $197^{\mathrm{b}} 10$, Ench., ZCP.7.490.g60, Tur. Mark Thes.i.486.37, Tur. Mark Thes.i.487.40.

\subsection{2 (-)i-variant $(5,1$ pretonic complex)}

\footnotetext{
${ }^{15}$ This is an example of a construction in which the definite article is reduced to nasalization:

i. $\quad$ i. a cobás mibís etar ṅdirainn hicomṡuidiguth i.e. the connection which exists between the two parts in composition

See also: Sg. $45^{\mathrm{b}} 19$.
} 
Tur. Mark. Thes.i.493.121, K. Aug. Thes.ii.2.5 1, K. Aug. Thes.ii.2.5'2, K. Bede Thes.ii. $14.31^{\mathrm{b}} 1$, K. Prisc. $60^{\mathrm{b}} 6$.

\subsection{Nominal Prefix $<$ etar $>$}

\subsection{1 (-)e-variant (32)}

Sg. $28^{\mathrm{b}} 3$, Sg. $52^{\mathrm{a}} 18$, Sg. $61^{\mathrm{a}} 6$, Sg. 61 ${ }^{\mathrm{b}} 2$, Sg. $68^{\mathrm{b}} 4$. a, Sg. $68^{\mathrm{b}} 4 . \mathrm{b}$, Sg. $73^{\mathrm{b}} 2$, Sg. $74^{\mathrm{b}} 8$, Sg. $75^{\mathrm{b}} 5$, Sg. 159 3, Sg. $166^{\mathrm{a}} 3$, Sg. $188^{\mathrm{a}} 7, \mathrm{Sg} .188^{\mathrm{a}} 12$, Sg. $197^{\mathrm{b}} 10 . \mathrm{a}, \mathrm{Sg} .197^{\mathrm{b}} 10 . \mathrm{b}, \mathrm{Sg}$. $197^{\mathrm{b}} 11$, Sg. $198^{\mathrm{a}} 2$, Sg. 198 3.a, Sg. 198 3.b, Sg. 202 2 2, Sg. 205 ${ }^{\mathrm{b}} 1$, Sg. $200^{\mathrm{b}} 10$, Sg. 207 ${ }^{\mathrm{b}}$ 9.a, Sg. 207 9 9.b, Sg. 220a 2, Tur. Mark Thes.i.485.22, Tur. Mark Thes.i.488.64, K. Aug. Thes.ii.2.6 ${ }^{\mathrm{a}}$, K. Aug. Thes.ii.7.14 1 , K. Bede Thes.ii.14.24 ${ }^{\mathrm{d}} 2$, K. Prisc. $66^{\mathrm{a}} 3$, Phil. Thes.ii.47.23.

\subsection{2 (-)i-variant (1)}

Ench., ZCP.7.492.g86.

\subsection{Conjugated Preposition $<$ etar $>$}

\subsection{1 (-)e-variant (10)}

Sg. $7^{\text {a }} 4$, Sg. $10^{a} 2$, Sg. $10^{\text {a }} 3$, Sg. $29^{b} 17$, Sg. $38^{a} 8$, Sg. $163^{b} 6$, Sg. $200^{b} 7$, Sg. $209^{b} 33$, Sg. $217^{\mathrm{b}} 9, \mathrm{Sg} .217^{\mathrm{b}} 11$

\subsection{Adverbial Conjugated Preposition <etar $>$}

2.5.1 (-e)-variant

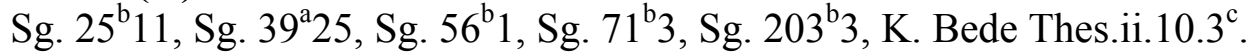

\subsection{2 (-)i-variant}

Sg. $90^{\mathrm{a}} 2$

\section{Würzburg Glosses}

\begin{tabular}{|l|c|c|c|c|c|c|}
\hline Variant & Prep. & Preverb & Prefix & Conj. Prep. & Adv. Conj. Prep. & Total \\
\hline$(-)$ e- & $28(+1)$ & 5 & $38(+1)$ & 0 & 10 & $81(+2)$ \\
\hline $\mathbf{( - ) i -}$ & 0 & 1 & 0 & 0 & 0 & 1 \\
\hline Total & $28(+1)$ & 6 & $38(+1)$ & 0 & 10 & $82(+2)$ \\
\hline
\end{tabular}

Table C: <etar> in the Würzburg Glosses

Table $\mathrm{C}$ tabulates the examples below.

\subsection{Prepositional <etar $>$}

\subsection{1 (-)e-variant (28, 1 dubious example [underlined]; 5 pretonic complexes)}


Wb. $7^{\mathrm{d}} 10 . \mathrm{a}, \mathbf{W b} .7^{\mathrm{d}} \mathbf{1 0 . b}, \mathrm{Wb} .9^{\mathrm{d}} 26, \mathrm{~Wb} .8^{\mathrm{c}} 20, \mathrm{~Wb} .10^{\mathrm{b}} 21, \mathrm{~Wb} .12^{\mathrm{b}} 12, \mathrm{~Wb} \cdot 13^{\mathrm{c}} 26 . \mathrm{a}, \mathrm{Wb}$. $13^{\mathrm{c}} 26 . \mathrm{b}, \mathrm{Wb} .13^{\mathrm{c}} 26 . \mathrm{c}, \mathrm{Wb} .13^{\mathrm{c}} 26 . \mathrm{d}, \mathrm{Wb} .13^{\mathrm{c}} 26 . \mathrm{e}^{16}, \mathrm{~Wb} \cdot 14^{\mathrm{b}} 10, \mathbf{W b} \cdot \mathbf{1 5}^{\mathrm{a}} \mathbf{2 9}^{17}, \mathrm{~Wb}$. $21^{\mathrm{b}} 15 . \mathrm{a}, \mathrm{Wb} .21^{\mathrm{b}} 15 . \mathrm{b}, \mathrm{Wb} .22^{\mathrm{d}} 17, \mathrm{~Wb} .23^{\mathrm{c}} 3, \mathrm{~Wb} .23^{\mathrm{c}} 28, \mathrm{~Wb} .26^{\mathrm{d}} 5^{18}, \mathrm{~Wb} \cdot 27^{\mathrm{c}} 15 . \mathrm{a}, \mathrm{Wb}$. $27^{\mathrm{c}} 15$. b, Wb. $\mathbf{2 7}^{\mathrm{c}} \mathbf{3 6}, \mathrm{Wb} .28^{\mathrm{b}} 03$, Wb. 28 $32, \mathrm{~Wb} .28^{\mathrm{d}} 25, \mathrm{~Wb} .28^{\mathrm{d}} 27, \mathrm{~Wb} .28^{\mathrm{d}} 31, \mathbf{W b}$. 29d 20, Wb. $30^{\mathrm{b}} 27$.

\subsection{Preverbal $<$ etar $>$}

\subsection{1 (-)e-variant (5)}

Wb. $8^{\mathrm{b}} 3 . \mathrm{a}, \mathrm{Wb} .8^{\mathrm{b}} 3 . \mathrm{b}, \mathrm{Wb} .9^{\mathrm{d}} 31, \mathrm{~Wb} .12^{\mathrm{c}} 32, \mathrm{~Wb} .13^{\mathrm{a}} 6$.

\subsection{2 (-)i-variant $(1,1$ pretonic complex) Wb. $5^{\text {b }} 34$}

\subsection{Nominal Prefix <etar $>$}

\subsection{1 (-)e-variant (38, 1 dubious example [underlined])}

Wb. $1^{\mathrm{b}} 18, \mathrm{~Wb} .4^{\mathrm{b}} 1^{19}, \mathrm{~Wb} .4^{\mathrm{c}} 24, \mathrm{~Wb} .8^{\mathrm{c}} 2, \mathrm{~Wb} .9^{\mathrm{b}} 19, \mathrm{~Wb} .12^{\mathrm{a}} 3, \mathrm{~Wb} .12^{\mathrm{c}} 32, \mathrm{~Wb} .12^{\mathrm{d}} 22^{20}$, Wb. $12^{\mathrm{d}} 8, \mathrm{~Wb} \cdot 13^{\mathrm{a}} 26, \mathrm{~Wb} \cdot 13^{\mathrm{c}} 1, \mathrm{~Wb} \cdot 13^{\mathrm{c}} 6, \mathrm{~Wb} \cdot 14^{\mathrm{d}} 32, \mathrm{~Wb} \cdot 14^{\mathrm{d}} 33, \mathrm{~Wb} \cdot 15^{\mathrm{a}} 1, \mathrm{~Wb} \cdot 15^{\mathrm{b}} 5$, Wb. $15^{\mathrm{b}} 20, \mathrm{~Wb} \cdot 15^{\mathrm{c}} 12, \mathrm{~Wb} \cdot 15^{\mathrm{c}} 15, \mathrm{~Wb} \cdot 18^{\mathrm{b}} 1, \mathrm{~Wb} \cdot 21^{\mathrm{a}} 8, \mathrm{~Wb} \cdot 23^{\mathrm{a}} 20, \mathrm{~Wb} \cdot 23^{\mathrm{c}} 19, \mathrm{~Wb}$. $24^{\mathrm{c}} 6, \mathrm{~Wb} .25^{\mathrm{d}} 17, \mathrm{~Wb} .25^{\mathrm{d}} 16, \mathrm{~Wb} .26 \mathrm{a} 14, \mathrm{~Wb} .26^{\mathrm{c}} 5$, Wb. $26^{\mathrm{c}} 7$, Wb. $26^{\mathrm{c}} 9, \mathrm{~Wb} .26^{\mathrm{d}} 12, \mathrm{~Wb}$. $26^{\mathrm{d}} 15, \mathrm{~Wb} .26^{\mathrm{d}} 25, \mathrm{~Wb} \cdot 27^{\mathrm{a}} 10, \mathrm{~Wb} .27^{\mathrm{b}} 26, \mathrm{~Wb} .29^{\mathrm{a}} 20, \mathrm{~Wb} \cdot 29 \mathrm{c} 10, \mathrm{~Wb} \cdot 30^{\mathrm{d}} 16, \mathrm{~Wb}$. $33^{\mathrm{a}} 11$.

\subsection{Adverbial Conjugated Preposition <etar $>$}

\subsection{1 (-)e-variant}

Wb. 5a3, Wb. $9^{\mathrm{b}} 2$, Wb. $13^{\mathrm{c}} 5$, Wb. $13^{\mathrm{c}} 6$, Wb. $15^{\mathrm{b}} 23$, Wb. $17^{\mathrm{d}} 19$, Wb. $19^{\mathrm{b}} 18$, Wb. $25^{\mathrm{d}} 26^{21}$, Wb. $27^{\mathrm{a}} 20, \mathrm{~Wb} .29^{\mathrm{d}} 23$.

\footnotetext{
${ }^{16}$ The form is written [et]er in Stokes and Strachan (1901: 587). Since the initial vowel is not certain, I have not counted this in the statistics in the paper. I count it within parentheses in Table C.

${ }^{17}$ In this example, the second conjunct is entirely elided:

.i. eteracride 'between their hearts [and him]'

${ }^{18}$ In this example, the second conjunct shows ellipsis of the accusative-marked noun.

.i. etermuntir nime et [mentir] talman 'between the people of heaven and [that] of earth'

${ }^{19}$ The manuscript is very difficult to read here. Stokes and Strachan (1901: 518) have (...e)tirchorsa, which is also a suggestion made by Kavanagh (2001: 413). Stern (1908: 536) read itirchorsa. According to the manuscript images found on the website of the library of the University of Würzburg, this is a distinct possibility, see the digitized manuscript at: http://vb.uniwuerzburg.de/ub/foliomagnifier.html?book=49294542\&page=9). In the Addenda and Corrections, Stokes and Strachan (1901: 725, n.518) note an opinion of Prof. Chroust that the letters tir are debatable. Therefore, this form is quite untrustworthy. I discount it in all the statistics but I count it in Table C within parentheses as an (-)e-variant.

${ }^{20}$ This is a possibly lengthened (-)e-variant: hétarcerta.

${ }^{21}$ This is a possibly lengthened (-)e-variant: étir.
} 


\section{References}

Bauer, Bernhard, 2015. The online database of the Old Irish Priscian Glosses. http://www.univie.ac.at/indogermanistik/priscian/

Breatnach, Liam, 1994. 'Varia II, 2. Prepositions with added vowel in relative compound verbs', Ériu 45, pp. 197 - 198.

Breatnach, Liam, 2005. A Companion to the Corpus Iuris Hibernici. Dublin: D.I.A.S.

Greene, David 1972. 'A detail of syncope', Ériu 23, pp. 232 - 234.

Griffith, 2013. The Milan Glosses Database. http://www.univie.ac.at/indogermanistik/milan_glosses.htm

Griffith, Aaron, 2016a. 'On the Old Irish third palatalization and the 3sg. present of the copula', Ériu 66, pp. 1-24.

Griffith, Aaron, 2016b. 'Pre-verbal ceta 'first' in the glosses (and some thoughts on the origin of the notae augentes)', presented at Maynooth University, Dec. 15, 2016.

Jasanoff, Jay, 1999. 'Some relative forms of the verb in Old Irish', in Eichner, Heiner and Luschütszky, Hans Christian (eds.) Compositiones Indogermanicae in memoriam Jochem Schindler. Prague: Enigma. pp. 205-221.

Lash, Elliott, 2014. The Parsed Old and Middle Irish Corpus. https://www.dias.ie/celt/celt-publications-2/celt-the-parsed-old-and-middle-irish-corpuspomic/.

Lash, Elliott, in progress. The Old Irish Minor Glosses Database.

Kavanagh Séamus, 2001. A Lexicon of the Old Irish Glosses in the Würzburg Manuscript of the Epistles of St. Paul (Dagmar S. Wodtko, ed.), Vienna: Verlag der Österreichischen Akademie der Wissenschaften.

Kelly, Fergus, 2009. A Guide to Early Irish Law. Dublin: D.I.A.S.

McCone, Kim, 1985. 'The Würzburg and Milan Glosses: Our Earliest Sources of 'Middle Irish', Ériu 36, pp. 85-106.

McCone, Kim, 1997. The Early Irish Verb. Maynooth Monographs I. Maynooth: An Sagart. 
Schrijver, Peter, 1994. "The Celtic adverbs for "against" and "with" and the early apocope of *-i', Ériu 45, pp. 151-189.

Schumacher, Schumacher, 2004. Die keltischen Primärverben. Innsbruck: IBS.

Stifter, David, 2014. 'Article Allomorphy in Old Irish', presented at the Teangeolaíocht na Gaielge XVI, Maynooth, May 10, 2014.

Stern, Ludwig, 1908. 'Bemerkungen zu dem Würzburger Glossencodex', Zeitschrift für celtische Philologie 6, 531 - 546.

Stern, Ludwig, 1910. 'Altirische Glossen zu dem Trierer Enchiridion Augustins in der Königlichen Bibliothek zu Berlin', Zeitschrift für celtische Philologie 7, pp. 475 497.

Stokes, Whitley and Strachan, John 1901.Thesaurus Palaeohibernicus: A Collection of Old-Irish Glosses, Scholia, Prose, and Verse, Vol. 1: Biblical Glosses and Scholia. Dublin: D.I.A.S.

Thurneysen, Rudolf, 1923. 'Ir. ègthiar', Zeitschrift für celtische Philologie 14, pp. 4 - 5.

Thurneysen, Rudolf, 1946. A Grammar of Old Irish. Dublin: D.I.A.S. 